\title{
Fugacidades e inanidades en Nada y Bracea de Malú Urriola.
}

\section{Fugacities and Inanities in Malú Urreola's Nada y Bracea.}

\begin{abstract}
Resumen
El presente trabajo propone analizar los dos últimos textos de Malú Urriola: Nada y Bracea, los cuales son parte de una trilogía por construir. Para este propósito, se revisarán ambos textos desde anclajes teóricos como el rizoma (Deleuze y Guattari) y el concepto de differance (Derrida) para ver el discurso poético como agenciamiento en la representación de la palabra poética en un otro; además de las mixturas de nociones estéticas como el despabilamiento, rebote, fugacidad e intermedio. Estos anclajes y mixturas se ponen en tensión en esta trilogía por hacer y así responder al cruce que se dan en estos textos entre la expresión poética y su inanidad como representación del ser que habla.
\end{abstract}

Palabras claves

Fugacidad, Inanidad, Poesía chilena actual.

\begin{abstract}
This paper aims to analyze the last two textbooks from Malu Urriola: Nada y Bracea, which are part of a trilogy to be constructed. For this purpose, we reviewed both theoretical and anchor text from the rhizome (Deleuze and Guattari) and the concept of differance (Derrida) to see the poetic discourse as an agent for representation of the poetic word in another, besides the Blend aesthetic notions as the perky, rebound, transience and intermediate. These anchorages and mixtures are placed in tension in this trilogy to be done and thus respond to the crossing that occur in these textbooks between poetic expression and its inanity as representing the speaking being.
\end{abstract}

Keywords

Transience, Inanity, Present Chilean Poetry. 
Para el lector habitual de esta poeta, es sabido que su primera publicación Piedras rodantes (Cuarto Propio, 1988) hasta Hija de perra (Cuarto Propio, 1998) tiene un carácter heterogéneo desde su discursividad estética y política. Malú Urriola ha propuesto, posterior a los textos señalados, una trilogía que condensa una suerte de poética de su propio discurso. Esta trilogía comienza con el libro Nada (2005), luego Bracea (2007). Queda en veremos el libro Vuela. Por lo tanto, la finalidad de este trabajo es la de analizar los dos libros de esta trilogía en proceso. Análisis que por lo demás, también, esta en proceso: por un lado, en espera del tercer libro y, por otro, de aunar los posibles tres fragmentos de análisis de cada libro en una mirada totalizante hacia una poética que se deslinde de estos tres textos.

Sobre el libro $\mathrm{Nada}^{1}$ se podría decir que es una condensación de las temáticas que Malú Urriola ya ha tratado en sus libros anteriores. El título tiene una "condición preñada", es múltiple su significación y conexión con distintas cosas. Nada de nadar en el mar de las palabras, en el infinito de lo que intentan decir, del silencio. Esto conectado con la Nada de algo baldío, de ese mar de palabras que es tan infinito que no se atribuye a ningún lado; una especie de vacío (silencio) entre tanta palabra (“La poesía es una luz que deja a tantos ciegos", 27).

Desde el principio de conexión y de heterogeneidad del Rizoma (Deleuze y Guattari, 1197), la palabra poética, en este texto, trata de hacer resonancia de las experiencias de la sujeto que habla en la búsqueda de su propia palabra personal. Esto provoca que el poema sea conexión del "pensamiento incoherente" de la sujeto con el poema mismo: "Este libro es un espejismo, un reflejo, /un pensamiento incoherente,/una silueta que me arranca del implacable día" (13). El resultado de esto es el recuerdo: la palabra poética como evocación e, incluso, de invocación, es decir, es la acción de ese "pensamiento incoherente" en la

\footnotetext{
${ }^{1}$ Numeraré las páginas utilizadas entre paréntesis para ambos textos de Malú Urriola de acuerdo a las siguientes ediciones: Nada. Santiago: LOM, 2005; Bracea. Santiago: LOM, 2007.
} 
escritura. Esa "incoherencia" es múltiple, sin lograr un sentido más que el del poema:

Cuando las palomas han emprendido el vuelo, no queda del vuelo sino el recuerdo.

Este libro es un recuerdo.

Un recuerdo que quiere salir interface [...]

La muerte y yo, por citar al recuerdo,

de vez en cuando arrojamos la ropa por el suelo,

y mientras sus manos desabotonan mi camisa,

yo acaricio los largos cabellos canos

que cuelgan hasta sus caderas. (13)

De ahí que el poema, en la generalidad del sentido en la escritura de Malú Urriola, es un filtro (o una transparencia como se dirá más adelante) que se ubica entre esos "pensamientos incoherentes" y la proyección hacia la "interface". Por lo tanto, el poema sería un filtro que ubica al recuerdo desde su categoría mimética en un sin sentido: nace esa "interface" que multiplica el sentido de la palabra poética.

Una posibilidad que podría existir en este punto es la apropiación de esta sujeto en sí misma. La palabra poética, con su sentido múltiple, que REBOTA en el propio sujeto. Sin olvidar que es esta misma quien lo genera. La sujeto que habla trata de legitimar esa "incoherencia" múltiple en la palabra para que ella misma trate de "traducir" lo que dice. Ese rebote podría ser la búsqueda de sí misma (una autotraducción) desde la incoherencia. Este juego no es para dar respuestas claras o, más aún, certezas para aliviar las incoherencias. Al contrario, es la propia sujeto que complejiza sus visiones: el acto de escritura sería un 
ejercicio de búsqueda de ambigüedades; una "fotografía" (la palabra poética, la imagen) que se saca y que se revela a sí misma:

Este es un libro tartamudo porque tútú, y yoyo, no somos los mismos, nunca lo hemos sido, yoyo soy un extraño, que no sabe para dónde, dónde, por qué, qué, qué fuerza hace llevar el yugo y trazar el arado de unos cuantos brotes de creatividad que da tumbos contra las paredes.

Las palabras que no escribo son las mejores, los vagabundos de metros, los proxenetas de bares de mala muerte, los adictos al margen como a las enaguas de una reina. (15)

La voz de esta sujeto hace rizoma con la palabra poética que al volver a sí misma (el rebote) no resuelve sus problemáticas, sino que las agudiza -que sería el sentido poético de este texto- para elaborar una travesía por el mar de las palabras. El acto poético es el "nado", un trayecto que involucra una cartografía de la travesía: los poemas, el libro. Además, como ya se dijo, ese "mar de palabras" en donde nada la sujeto que habla se inserta en el vacío de sí misma, en la inutilidad de sí misma:

Escribir es un ejercicio innecesario, las hojas secas del otoño cuando un arremolinado viento las eleva, escriben mejor que nosotros, [...] 
La poesía es una luz que deja a tantos ciegos. (27)

Cuando la sujeto habla consigo misma (en el rebote de la palabra), se distancia de sí misma: la sujeto habla con su yo, que es una de las tantas partes de este sujeto fragmentado. La escritura es un destello de sí, es el flash que circunda al yo. Pero es el mismo lenguaje (que sería la misma sujeto), que no consigue hablar de sí misma. Por esta razón, existe esa "incoherencia", esa multiplicidad de flashes que tratan de asir a una sujeto esquiva hacia sí. Es decir, la sujeto retrataría su transparencia para salir del silencio: la escritura como un aullido no plausible que se transforma en tartamudez. El habla como rupturas (por ejemplo en la página 15)) de lo que se quiere decir.

En conclusión, a la sujeto sólo le queda la transparencia para sostenerse, para no seguir interrumpiéndose en las incoherencias propias. Esa transparencia que está al filo de ser nada: la sujeto que se da cuenta de su propia desaparición. La transparencia aparece como aviso de ese filo. Es decir, la sujeto que no busca significarse en nada (principio de ruptura asignificante del rizoma). Desde ese lugar -la cartografía de su travesía- alterna su línea de fuga - en la escritura y desde la escritura- para desplazarse en prolongaciones de sus contradicciones:

\section{Ah, las palabras como miles de piedrecillas}

que si los juntásemos de una vez, lo dirían todo.

La compasión de sí mismo, degolló al cordero. [...]

Y la habitación se ensancha como se ensanchan los días

$Y$ despiertas para olvidar

Que sobrevives a la más alucinante de las pesadillas.

Quién anda afuera? Quién? 
Soy la nada, que nada dice y nada ve,

La que nada recuerda

La que recuerda todo. (70)

"El rizoma no se deja reducir ni lo Uno ni a lo Múltiple [...] No tiene ni principio ni fin, siempre tiene un medio por el que crece y desborda" (3). Ese medio al cual aluden Deleuze y Guattari es el deslinde o el filo que se quiere construir. Deslinde que certifica y legitima a la nada como la tartamudez que habla (la incoherencia, palabra ya sumergida en la sujeto). Despabila el estado caótico en palabras en un orden. La palabra poética, quiérase o no, aquí, remece a la sujeto a plasmar esa nada, esa travesía (esa cartografía del viaje) por ese mar de palabras que se ordenan y construyen poemas: ese despabilamiento elabora un ánimo en la escritura de los poemas, la ira de hacer conciencia de que las palabras ordenan; el estado primigenio sería el silencio que la sujeto reverencia como el campo o lugar perteneciente a la imaginación. Por este motivo, la poesía sería un ejercicio contradictorio: por un lado ordena el caos imaginario -el silencio- a través de las palabras y por otro plasma el rebote -las contradicciones y las incoherencias- que la sujeto inscribe desde su transparencia que recorre el filo de la nada:

Los días pasan aprisa y ni aún mis dedos

consiguen rozar los pétalos de esta huraña entrega.

Está a mi lado y su alma enteramente mía.

Se aleja y mi alma es enteramente suya.

La poesía es un invento cruel.

Pensamientos que de puro salvajes insisten, mientras los pájaros cantan magistralmente afuera.

Ha amanecido y la ciudad despierta. 
Oh, welcome to reality.

Nada soy,

en ningún lugar,

nadie. (75)

La idea acá no es la construcción de identidad, menos de dar perfiles de verdades; sino que el lugar está al otro lado del puente, es la oposición, la nada. Y es ese mismo lugar el que provoca ira: son las palabras las demostrativas de ese estado y no las pulsaciones improvisadas -las incoherencias- de la imaginación. Es el imposible de este proyecto: escribir el silencio. Es la crisis por no conseguir la autonomasia de lo que se quiere decir. Un imposible parecido o ya visto en Rimbaud y del que Mallarmé se da cuenta para construir sus poemas característicos.

Ese imposible de esta sujeto es la ira del orden que provocan las palabras:

Que nada digan las palabras,

que no mientan más,

que no sobornen,

que no encubran.

Que no mienta el silencio que cuando calla miente

y esculpe la duda,

de si anochece, o anochezco (79)

\section{Bracea: la fugacidad y la inanidad del ser}

"Soy Nada. / Nunca seré algo. / No puedo

desear ser nada. I

Más aún, llevo en mí todos los sueños del mundo”, Fernando Pessoa. 
Trato de entender la palabra bracea en el contexto de la lectura del libro de Malú Urriola (2007). Bracea como acto del nado (antítesis de nada, el femenino, el injerto metafórico que se desprende de su libro anterior). Ese acto que implica cierto esfuerzo del cuerpo en el agua. Acto seguido: ese "cierto esfuerzo" como una incomodidad del cuerpo al moverse en ese espacio. Bracea, la palabra en la incomodidad de lo que uno es. Me parece que esta parte la dejaré por un rato.

Bracea, me parece, una acción que involucra un estado, más bien, un estado fugaz y de inanidad del propio sujeto, de una vibración que está en latencia, pero que también se mueve. Bracea como el intermedio, un entre en lo que se pretende hacer y lo que se desea lograr. El intermedio de lo que se quiere ser y lo que no.

Para este texto, revisaré la figura del otro desde la perspectiva de un yo que "quiere estar fuera del lenguaje" en relación a un tú: "decirse en otro", lo cual tiene directa relación con el concepto de différance de Derrida. La noción de fugacidad como medio y estado del yo en su relación con el lenguaje, lo cual rebota en que la escritura sea un reflejo del sujeto. Estos elementos conllevan a distintas miradas, unas más parciales que otras para entender este texto como un conjunto de discursividades en estado de construcción.

\section{El otro, la fugacidad y el intermedio}

A lo largo de todo el texto las presentaciones de dualidades se van conformando en un ejercicio situacional. Esto es: cada personaje que participa del discurso -incluye a la hablante, la cual va creándose desde esos otros-. Los más visibles en el texto son:

- La hablante con su hermana

- $\quad$ Las dos madres 
- El perro partido en dos con J.P Junior

- La hablante con Gabriela Mistral

Dejo para más adelante una otredad menos visible, la de la hablante con una de las dos madres.

Si contamos con todo el taller de herramientas del postestructuralismo, en especial, la de la noción de différance derridiana (Derrida, 2005), puedo, en un pequeño pestañeo, advertir el sentido ontológico que convocan los versos en la noción establecida de "crearse en otro". Ser a partir de lo que no soy invita a una acción de reflejos múltiples. Para el caso de este texto, dichos reflejos parten de una negatividad. Dicha negatividad puede mirarse como un "decirse en otro" como dice Pessoa, es decir, en un deshabitarse que deviene de una alteridad que refleja una inanidad del ser, el complemento de esa negatividad sería el otro, el heterónimo como cuestionamiento del sentido humano en la palabra poética para ficcionalizarse en ese otro. Lo importante acá es cómo ese yo es escéptico de sí mismo y cómo nos muestra esa distancia consigo mismo: el escepticismo desde sí, el yo vuelto a ser repetido para superar o acentuar la inanidad.

La hermana que sonríe en la foto, mientras la otra no; ambas como siamesas mentales que van al mismo paso, al mismo paso de su imagen grotesca de sí mismas. El perro cercenado en dos partes por un tren, las cuales dependen una de otra como vidas independientes que tiene la misma "mirada temblorosa" cuando J.P. Junior "quedó con los ojos fijos al cielo viendo algo que/ nuestro perro también vió" (96). La hablante que asume, en parte, la cosmogonía de la Mistral al representar el espacio colindante. Pero ese espacio representado es la sobra de lo que de lo que la Mistral reflejó: "El poema (que la hermana le lee a la hablante) dice cosas que suenan a las aguas del río, / cuando arrastra las piedras y las ramas de los sauces [...] La mujer que lo escribió está enterrada aquí/ Ella se fue de aquí/ Aquí sólo regresó un esqueleto" (95). Son la sobras que la hablante rescata para confirmar algo que se fue, habla desde el esqueleto de la Mistral. Esto es: la hablante como voz abismal de una representación grotesca y disminuida en su identidad: el otro que contiene lo que no es. Un significante mistraliano que 
repara en la vacuidad que se hereda de un esqueleto. Por otro lado, las dos madres: una que sueña con su constante escape a Barcelona en busca de un viejo amor y la otra como funcional a las labores domésticas.

Todos estos ejemplos se van entramando, se van conteniendo unos con otros para promover un ejercicio de la otredad desde la negatividad ontológica: “crearse desde lo que no soy", podría volver a repetir, crearse desde otro, es lo que muchos pueden decir. Lo importante, creo yo, en estas différances es hacia dónde van estas otredades. Mi primera impresión es que apuntan al lenguaje. Este lenguaje como fugacidad y como estado intermedio.

La fugacidad se manifiesta aquí a través de la adquisición del lenguaje. En este caso, dicha adquisición está ligada con los recuerdos, ya sea de la familia, el padre y sus apariciones, en especial con el abandono que éste hizo con la hablante y su familia. Por otro lado, lo fugaz de la memoria que repite una y mil veces lo que uno es (redacción). Es el ejercicio de bracear, de esa incomodidad de ser parte de una representación en el lenguaje y a su vez de representar, en el mismo lenguaje, lo que se vive. Bracear consigo mismo sobre las palabras que quiero usar para dictar el mundo. Repetición tras repetición de las palabras para apelar a un recuerdo, a una memoria de sí mismo: sujeto y palabra, elementos que tratan de cruzarse para tratar de decir algo. El sujeto que quiere hablar, pero la fugacidad de su ser plasma palabras que quedan como un recuerdo distante de lo que una vez quiso ser. Por lo tanto, las palabras tratan de volver a habitar a esta sujeto para que recuerde lo que dice y recuerde que existe, ya sea, en este caso, en un otro, el doble de sí. Ese bracear que está entre lo normativo de la lengua y lo que estima para crear otros mundos que la memoria dirá: el acto de bracear es el balbuceo entre las palabras instaladas en el mundo y las palabras que uno puede instalar aquí. Constituir un horizonte distinto de las palabras para cambiar su sentido. Ese ejercicio poético demuestra que la poesía es un acto fugaz: las palabras establecidas en el aquí y en el ahora, mientras las otras palabras que se quieren que aparezcan están en el trabajo de la búsqueda poética. El braceo sería la palanca que impulsa, desde lo que está, un nuevo horizonte de representación: 
Lo que extraña mi hermana es pronunciar la palabra padre. Yo extraño las palabras que no conozco .(101)

Las expectativas del juego poético en este texto sería la de contaminar el mundo de las palabras fijas y normadas con palabras que desde esta misma normativa convencional adquieren distinto sentido en el ejercicio poético. Lo central de este llamado ejercicio es que esas palabras, con distinto engranaje de sentido, se dan en la fugacidad del estado, condicionamiento y contención de la palabra poética:

La mariposa bracea, y braceando se retira tan lejos del cardo blanco, Que se ha quedado vibrando como queda el alma cuando el dolor con ella hace lo suyo. (11)

Esta fugacidad relatada está acompañada de otra figura, la del intermedio. Ambas son complementarias y dependientes. Un intermedio como un entre, un vaivén que se resiste a mantenerse fijo (al igual que el epígrafe de Juan Gelman del capítulo "La casa": "Hay que aprender a resistir. / Ni a irse, ni a quedarse. / A resistir"). Este intermedio es lo actitudinal, al igual que lo fugaz, de la hablante, pero distintamente desde la conciencia del acto poético. Esta conciencia nace desde la negatividad del ontos en no querer ser lo que es, como antes había dicho: el intermedio es la bisagra que comparte lo que se intenta ser con lo que no. Este vaivén que posa su nariz en ambos lados hace que la sujeto que habla no esté en ningún lugar fijo. Es una "intrusa" que fisgonea distintos planos para acondicionar la fugacidad de la palabra poética. El intermedio que recoge las palabras y las modifica para constatar el descontento de lo que la hablante es: 
Soy una intrusa de la relación que mantiene el cardo con el viento y la envidio:

Pues yo quisiese ser ese cardo abrazado por el viento y no ser lo que soy. (11)

Como decía anteriormente, ambas figuras, fugacidad e intermedio, son complementarias y dependientes. Ambas producen una interrupción en el mundo normado por palabras funcionales. Ambas contaminarán a esas palabras. ¿Acaso será la pretensión huidobriana de crear mundos nuevos? ¿Acaso será un dialogismo con Nelson Goodmann sobre las maneras de hacer mundos? (Goodman, 1990) A primera vista puede sonar a eso, pero creo que acá hay una distinción: es el carácter que asume la palabra (aquí vista desde su nacimiento en la fugacidad) más el alcance de la sujeto que emite desde sus ontos dispersos de representación (aquí llamado como intermedio). Se puede discutir, entonces, que sujeto y palabra (y viceversa) son lo mismo. Pero, por ahora, dicha discusión no la asumiré para este caso. Creo si, acercarme y, por lo tanto, distanciarme, que en la relación sujeto/palabra hay un espacio o, siguiendo la lógica que aquí se plantea, un estado de relación y dependencia mutua como lo plantee anteriormente, pero creo, también, que está sujeto a una situación intermedia, y dependiente sólo de esta situación, no afloraría la fugacidad de las palabras. Estoy queriendo decir que la relación sujeto/palabra merece, en este caso, una discusión sobre el estado en que se encuentran la sujeto y sus palabras para hacer funcionar el ejercicio poético. De lo que en el fondo estoy hablando es de la crisis de la experiencia que Benjamin dibujó en su texto El narrador (1991), pero, en este caso, visto desde la incapacidad de compartir experiencias desde sí, por eso la salida es hacerse de otro que supere la inanidad y que la constate como algo que de ante mano siempre va a estar. Siguiendo a Benjamin en este texto, el ejercicio poético sería el testimonio de dicha crisis de la experiencia. Como ejemplo de lo dicho es el verso que sigue a la cita anterior: "Un cardo contra el viento, no es lo mismo que la condena de /ser dos" (11). 
CAtEdral TomadA: Revista de crítica literaria latinoamericana / Journal of Latin American Literary Criticism Fugacidades e inanidades en Nada y Bracea de Malú Urriola.

\section{El texto como reflejo de sí mismo}

De acuerdo a la historia de la literatura moderna occidental, hay una noción (de varias) que se refiere a que el texto literario muestra su propio proceso de creación. Esto es: en el periplo del relato hay alguien al interior del texto que escribe lo que ya se está contando. Ese alguien no es el narrador propiamente tal, sino un personaje que intercede en el relato. Ejemplos ocurrentes para el caso: el moro Cide Hamete Benengeli en el Quijote o el viejo gitano Melquiades en Cien años de soledad. En palabras postestructuralistas, sería el significante tras otro significante - un otro narrante- que va relatando o construyendo el relato a contar.

Para el caso de Bracea pasa algo similar. La sujeto que habla (un significante) continúa el relato de la segunda madre (otro significante) que ella misma dejó. Justo, después del invierno: "Nuestra madre guardó la Oliver y dedicó sus días a cuidar a nuestra madre, / a la siembra del choclo, a los chanchos, a batir la nata de la leche/ y a enseñarnos a escribir. /Pero nosotras ya habíamos aprendido" (98). En la Oliver, esa otra madre iba escribiendo los sucesos familiares (incluyendo las cartas a su amado en Barcelona); la máquina, al ser guardada, la continúa, en su uso, la hablante: "Volví a sacar la Oliver, el papel, coloqué la cinta./ La madre deja de padecer la historia para escribirla" (107). La segunda madre era la voz que relataba la historia contada en el texto, pero dejó de contar para cuidar a la otra madre: dejó de teclear la máquina para funcionar en las labores domésticas. Se formalizó. La hablante, por lo tanto, continúa la escritura dejada de lado. Hay un matiz: la hablante asume la voz de la segunda madre. Ambas son una en la escritura. Ambas son las enajenadas, las brutas de la familia que no se han formalizado. Por un lado, la segunda madre cuida a la primera y sigue la hablante la escritura hasta su supuesto suicidio. Por otro lado, en ambas se entiende que la escritura es un ejercicio de exorcización de los padecimientos. Aquí la escritura tiene un sentido depurativo -catártico- de la negatividad del otro y viceversa: "La madre deja de padecer la historia para 
escribirla" es la consigna que establece la poesía como medio de dualidades de sujetos hablantes (segunda madre y hablante): es el otro que salva a la primera. Entre esas dos voces circula la escritura como unión o bisagra de esas dos voces que son una a la vez.

\section{Bibliografía}

Urriola, Malú. Nada. Santiago: LOM, 2005.

---. Bracea. Santiago: LOM, 2007.

Deleuze y Guattari. Rizoma. Valencia: Pre- textos, 1997.

Derrida, Jacques. De la Gramatología. México: Siglo XXI, 2005.

Goodman, Nelson. Maneras de hacer mundos. Madrid: Visor, 1990.

Benjamin, Walter. El narrador. Madrid: Taurus, 1991. 